\title{
Due diligence neglected: managing human resources and organisational culture in mergers and acquisitions
}

\author{
F.M. Horwitz* \\ K. Anderssen \\ A. Bezuidenhout \\ S. Cohen \\ F. Kirsten \\ K. Mosoeunyane \\ N. Smith \\ K. Thole \\ A. van Heerden \\ Graduate School of Business, University of Cape Town \\ Breakwater Campus, Private Bag, Rondebosch 7700, Republic of South Africa \\ fhorwitz@gsb.uct.ac.za
}

Received January 2002

\begin{abstract}
The aim of this article is to identify attributes of organisational culture and human resource practices required for successful transitions in mergers and acquisitions. Using primary data from five case studies on mergers and acquisitions, findings show that where neglect of two key 'soft' due diligence factors of cultural and human resource compatibility occurs, transition and effective integration of the new entity is hampered. The need for a coherent integration plan including joint teams, effective communication and other appropriate human resource practices is considered vital for successful acculturation. A model for both managerial policy and further research is proposed.
\end{abstract}

*To whom all correspondence should be addressed.

\section{Introduction}

Mergers and acquisitions (M\&A's) are increasing with competitive and financial pressures of globalisation. Through M\&A's, firms seek strategic positioning, industrywide consolidation, increased market share and shareholder value, synergy through economies of scale, revenue enhancement, risk reduction, shared cost of product development and improved access to markets and new technologies (Birkinshaw, Bresman \& Hakanson, 2000; Fisher, 1998; Krugman (2001); Marks \& Mirvis, 1996; Walker \& Price, 2000). Although M\&A's are different legal transactions, they tend to be treated synonymously in the literature, primarily because in practice a merger is rarely a marriage of equals (Cartwright \& Cooper, 1996). A merger is the joining or integration of two previously discrete entities. It occurs when two companies integrate to form a new company with shared resources and corporate objectives (Ghobodian, James, Liu \& Viney (1999). An acquisition occurs when on organisation acquires sufficient shares to gain control or ownership of another organisation. Other positive organisational effects include acquiring new capabilities and resources, cutting costs and defending against a (hostile) take over (Price, 1999).
The central purpose of this exploratory study is to identify attributes of organisational culture and human resource (HR) practices necessary for successful cultural transition in M\&A's. Four knowledge types have emerged in previous merger and acquisition (M\&A) research, namely financial economics, strategic management, a process perspective and organisational behaviour (Birkenshaw et al., 2000). These are often practically inter-related, but reflect different theoretical perspectives. This study identifies common developments and lessons for effective HR management and cultural integration from case study research of five mergers and acquisitions (M\&A) considering organisational behaviour and HR factors. Previous research focuses on reasons for M\&A failure or success (Cartwright \& Cooper, 1996; Denison, 1990; Ernst \& Young Consultants, 1999; Harris, 2000; Horwitz, 2000; Walker \& Price, 2000). A successful merger relies on exploiting core competencies and intellectual capabilities common to the two organisations (Ghobodian et al, 1999). Conventional due diligence has focused on financial and strategic aspects and ignored cultural and human resource integration and alignment. Human resource ssues tend to be considered only when financial and legal matters have been finalised 
(Ashkenas, DeMonaco \& Francis, 1998; Stopper, 1998). Ignoring organisational culture differences may have high long-term hidden costs. A merged entity may try to improve growth and productivity, but with a fragmented organisational culture. This investigation highlights the importance of these factors in relation to the broader M\&A literature. Building on process and organisational behaviour perspectives, a model for effective cultural and HRM integration, is proposed.

\section{Cultural factors in mergers and acquisitions}

Success of an M\&A can be measured by assessing economic value added, more efficient use of resources, and impact on organisational culture (Birkenshaw et al, 2000). Several studies have identified key performance factors in M\&A's (Bezuidenhout, 1999; Birkenshaw et al, 2000; Cohen, 1999; Hespeslagh \& Jemison, 1991; Kellog \& Silva, 1998; McDonald, 1999; Risberg, 1997; Walker \& Price, 2000). A link exists between M\&A planning, management practices, and coherence of organisational culture and performance (Beard, 1999; Bruckman \& Peters, 1999; Kirsten, 1999) Dennison (1990) suggests four integrated mechanisms of organisational culture may influence its performance: organisational direction and shared purpose, early employee involvement, consistency, the impact of a strong culture on firm performance, and integration of a widely held system of norms and expectations. Propensity to adapt leadership, mindset and systemic changes enhances a merged organisation's chances for survival and growth. Disparate cultures may hamper integration around new norms, work practices, individual and organisational identity. A strong organisational culture can create competitive advantage, increase motivation, and organisational effectiveness if articulated integration processes are agreed and implemented (Kotter \& Heskett, 1992).

\section{The implications of culture types for inter- organisational combinations}

Success of a M\&A hinges on the ability of decision-makers to identify a potential merger partner or acquisition target with a good strategic and cultural match (Heller, 2000; Mosoeunyane \& Thole, 2000). As financial and strategic considerations may outweigh selection criteria based on cultural similarities, combinations between organisations of different culture type occur. It is apt to ask whether a particular combination of cultures has more chance of success than another combination. For example, the combination of a 'role culture' with a 'task culture' has more chance of success than a 'power culture' with a 'person/support culture' (Cartwright \& Cooper, 1996). These authors posit a typology of merger integration referring to traditional, open and collaborative marriages. These depend on the motive for and power relations in a M\&A. As the objectives of 'traditional marriages' and 'collaborative marriages' are different, acquirers require different characteristics in their partners. Success for a traditional marriage depends on the ability of an acquirer to change the culture of the acquired, whereas integration in a collaborative marriage depends on willingness to compromise. The degree of dissimilarity between two culture types may determine the degree of accommodation needed to attain a new 'best of both worlds' culture.

The more dissimilar the cultures, the greater the resultant cultural shock, particularly if the M\&A was not voluntarily chosen (Cartwright \& Cooper, 1996; Cohen, 1999; Van Heerden, 1999). Different cultural types may put differing constraints on individuals. Individuals assess the culture of the other partner by the value they attach to preserving their existing culture, or the extent they perceive the culture of 'the other' to be attractive. Potential outcomes for the organisation include member assimilation, integration, separation, and deculturalisation. Successful marriages are an outcome of the cultural dynamics and power relations in the combinations. The culture types of both organisations before integration play a crucial role in determining whether an acquired culture will change or integrate. Cartwright and Cooper (1996) maintain that cultural similarity is not a precondition for satisfactory assimilation. Traditional marriages, which most mergers are, are likely to be successful if the intended direction of culture change is seen as increasing employee participation and autonomy. Meaningful integration through a collaborative marriage is more likely to occur where there is potential to create a 'best of both worlds'. Bate (1990) posits four broad approaches an acquiring firm may take, each with differing effects: aggression/hostility, conciliation, corrosion and indoctrination. Conciliation and collaboration are more likely to be associated with establishing cultural fit prior to a M\&A than other approaches (Horwitz, 2000; Mirvis, 1985; Rao \& Swaminathan, 1995).

\section{Human resource practices and cultural integration}

Merger and acquisition strategies seek competitive advantages which organic growth cannot achieve. Power relationships between parties influences the manner in which HR and cultural integration occur. In an acquisition there are winners and losers. There is more overt employee resistance to change in hostile acquisitions than in voluntary M\&A's. Here the HR policies and practices of the dominant party may be imposed. Feelings of defeat may affect merger outcomes in setting the direction of future cultural change and HR integration.

Mirvis (1985) notes adverse HR effects such as an initial closing of ranks, a shared sense of loss, and over-confidence of acquiring management in estimating the ease and speed of achieving integration. 'People problems' and the time scale of this process are often underestimated. Mergers and acquisitions may result in retrenchments and unplanned labour turnover. Individuals may be unable or unwilling to fit into the new organisation, experience high levels of stress, with a fear of loss of identity and status, become obsessed with survival, and experience family repercussions. Price (1999) and Horwitz (2000) outline four phases usually over a period of two to three years: a start-up (3-9 months), transitional (3-6 months), and integration (7 months -2 years), and closure. Integration and HR planning has not been sufficiently developed as most organisations do not follow clearly defined steps and coherent processes (Ashkenas et al, 1998). Price (1999) cites commonly 
recurring problems including role conflict and ambivalence, poor communication, lack of a clearly defined transformation process to manage human resources issues, underestimating the need for guidance and support and absence of an integration strategy. These factors and cultural clashes between merging firms are causes of failure. Ashkenas et al's (1998) acquis ition model has four stages. First a pre-acquisition stage with due diligence, negotiation and closing the deal. Second, a foundation building stage with a launch, and merger integration and strategy formulation. Third, rapid integration by implementing an integration plan, and progress assessment. Fourth, an evaluation and adjustment of the long term plan capitalising on successes.

A distinction can be made between 'hard' and 'soft' HR practices in M\&As. The former includes pay differentials between the two organisations, trade union policy and density, differences in employment benefits such as pension funds, level of in-company training commitment, and possible retrenchments. Tetenbaum's (1999) model, the focus of our study, is more closely associated with 'soft' HR issues, though it does not explicitly distinguish between these types of practices. Both are critically important in the effective integration of post-merger entities. The model identifies human resource practices integral to cultural integration. These include early employee involvement, establishing an integration team(s) with identified briefs, building organisational capability, strategically aligning and implementing appropriate systems and procedures, managing culture, managing post merger drift by managing the transition quickly, clear communication and information flows and streamlining systems and procedures. 'Hard' HR issues have to be dealt with through these systems and processes. Pritchett and Pound (1997) and Ashkenas et al (1998) hold that M\&A integration is not a discrete phase of a deal but rather a process beginning with due diligence focusing on leadership styles, management structure, key roles, reporting relationships and integrated HR support systems. Career affecting decisions should be announced and implemented soon after the deal is signed. Merger specific incentive programmes and strategies to prevent avoidable turnover of high quality employees are important. Failed mergers often reflect sloppy 'soft' due diligence. Key critical success factors for such a cultural audit include understanding management strengths and weaknesses, needs/opportunities for organisation restructuring and redesign, review of existing $\mathrm{HR}$ practices and systems. Salient differences in corporate culture need to be addressed. In the transition period, resistance to change is common. Cisco System's approach to maximise M\&A success includes criteria to determine suitability of an acquisition and empowered teams and programmes to increase speed of assimilation (Ashkenas et al, 1998). Success criteria include developing a shared vision, and creating the right chemistry or cultural compatibility, careful scrutiny of management styles, competencies, organisational structure and cultural fit (Heller, 2000; O’Reilly, 1998).

"We've killed nearly as many acquisitions as we've made...even when they are very tempting. I believe it takes courage to walk away from a deal. It really does.
You can get caught up in winning the acquisition and lose sight of what will make it successful. That's why we take such a disciplined approach."

John Chambers, CEO Cisco Systems, 1998

Cisco Systems establishes integration teams in order to integrate new companies into Cisco as quickly as possible. Integration takes place at altural, structural and systemic levels. Culture integration includes the assignment of 'buddies' and special orientation sessions.

\section{Research methodology}

\section{Central focus}

The central focus of this exploratory investigation, is on two vital interrelated attributes of success, that is, human resource and cultural factors in the M\&A process, using largely qualitative data. Such data may have potential interpretation biases. Findings from five case studies are expected to add further insight to the importance of "soft" due diligence assessment, and critical success factors in M\&A implementation, particularly on HR and cultural issues. Merger approaches and practices in South Africa (SA) are similar to those identified in the literature. Participating firms from different sectors in SA were Futuregrowth Investments, Macsteel International, Momentum Life, Pathology Services and Protea Industrial Chemicals (Pty) Ltd.

\section{Sampling and company background}

Each M\&A had occurred within the past four years. The sectors included insurance, financial services, pharmaceuticals, medical research and iron and steel. Convenience sampling was used, based on companies willingness to participate in the study, and where the research team had access to employees and information such as policies and procedures. Some of these M\&A's had receiving considerable media coverage. Futuregrowth Asset Management is the smallest of the companies in respect of number of employees, though it managers assets over R 1 billion. It was established as a black empowerment investment company as a result of an acquisition by FirstRand group, the largest financial services company in $\mathrm{SA}$ in terms of market capitalisation. It was previously part of Southern Life Insurance Ltd. Momentum Life Assurance is one of the four largest insurance companies in SA. It has subsidiaries in merchant banking, such as Rand Merchant Bank, asset management, and health insurance. It is also a holding company for short-term insurers, and has engaged in a number of M\&A initiatives over the past decade. Macsteel International (Pty) Ltd a privately owned steel manufacturer merged with Iscor a state owned enterprise to form the largest steel manufacturing concern in Africa. This was in part related to privatisation measures. The company has over 15000 employees. Pathology Services is a merged entity of two large health sector firms, employing over 350 people. Protea Industrial Chemicals (Pty) Ltd is a diverse manufacturer of various chemicals used in sectors such as 
plastics, petrochemicals paints, water care and textiles. It has acquired a number of smaller firms in these sectors.

\section{Data collection and analysis}

Data were obtained from: (1) semi-structured interviews with the senior human resource executive in each of five organisations. An interview schedule was designed based on relevant literature; (2) interviews with the chief executive officers in each of the five firms, and with two senior line managers in three of the five organisations. In the other two, three senior executives in each were interviewed; (3) focus groups in each of the five participating firms which comprised 12-15 employees stratified by department and organizational level; and (4) documentary evidence, such as company policy statements and written HR procedures. Given the differing industry/sector type and the convenience sample drawn, largely aggregate data was analysed, as departmental differences within and between firms did not reveal significant comparable findings in the content analysis of qualitative interview data. Differences were found between senior management interview and employee focus group data, suggesting differing perceptions at different organizational levels. Hussey and Hussey (1997) refer to content analysis as a diagnostic tool of qualitative researchers, used to make sense of open-ended material. A derivation of content analysis, namely grounded theory was used (Easterby-Smith, Thorpe \& Lowe, 1991). It is pertinent for non-standard data, for example transcripts of in-depth interviews (Weber, 1990). Common or contradictory themes, patterns and trends were drawn from the data. Although focus on five M\&A's may limit broad generalisation from the findings, it adds further empirical support for trends, patterns and issues raised in the literature. The central focus of the case approach is on cultural transition and allied human resource practices - two key sets of factors in M\&A performance. The study does not aim to determine a direct relationship between M\&A and subsequent financial performance of the new entity. Other variables such as strategic choice, financial due diligence, market forces and competitiveness of operations, have not been included. Two conceptual frameworks formed the basis for interview questions. First, semi-structured questions using Cartwright and Cooper's (1996) typology of role, task, power and person/support cultures, was used. Second, Tetenbaum's (1999) typology of key HR practices important in M\&A integration was used in the semistructured interview design. These included questions on:

- $\quad$ early employee involvement

- establishing integration teams

- building organisational capability

- $\quad$ aligning HR systems with emergent strategy(ies)

- managing cultural change

- communications processes

\section{Findings}

\section{Culture types,'soft' due diligence and effective post merger integration}

All the M\&A's were analogous combinations of organisations with disparate culture types. The type of partnership agreement between the organisations depended on the motive, objective and power dynamics of the merger. Following the merger, four of the five organisations showed characteristics of a dominant culture. Only one conducted a 'soft' due diligence audit to determine organisational fit prior to the transaction. Three merged organisations lacked a clear merger implementation strategy according to employee focus groups responses. There were some differences between organisations where the integration was actively managed or initiated by a specific person or group. There were limited similarities in the transition processes of the organisations, and where these similarities were present, they were primarily examples of what not to do. Only two of the five merged companies had a definite sense of urgency during the merger process according to focus group respondents. Most indicated that employees experienced uncertainty regarding their positions in the new organisations.

Employee focus group data revealed that communication in four of five merged organisations could have been managed much more effectively. In addition to overall cultural changes, almost all the organisations showed significant changes in individual cultural dimensions. Most employees in focus groups from three of the organisations felt that their respective organisations were not operating as fully integrated units. All the M\&A's were organisational combinations with contrasting culture types. Based on interviews with senior executives, three of the M\&A's were a result of a combination of culture types. Both the Momentum Life and Macsteel International mergers represented combinations between role and task culture types (Cartwright \& Cooper, 1996). Although in two of the M\&A's where the respective partners had predominantly role cultures, they also had traces of autocratic power cultures. Although Pathology Services did not seek to define the culture type of each organisation, it had traits specific to both role and task cultures. In another firm the transition process a shift from a role to a task culture occurred. The type of partnership agreement between the organisations depended on the motive, objective and power dynamics of the merger. Interviews with senior executives indicated that the underlying objectives of three of the five firms were financial, and strategic - seeking to enter new markets, achieve economies of scale and achieve growth. Most of the M\&A's sought to redesign the weaker organisation, bringing in specialised knowledge and expertise to gain synergy. The aim of these traditional marriages was radical and wide scale change, in mo st cases with wide adoption of practices, procedures, philosophies and culture of the dominant firm. In one case, Pathology Services, a more collaborative approach occurred. The above are supported by differences between the culture attributes before and after most of the M\&A's. Metaphors used in focus groups indicated that Momentum Life for example, had a stronger culture which was adopted in the new organisation 'Some metaphors used by employees and ex-employees in two firms were that they were "pulled apart", "completely swallowed up" and "already in limbo" due to restructuring', 'feeling overwhelmed' and 'taken over completely'. In one case, a high performance work culture in a smaller firm made it sufficiently flexible to assimilate the dominant culture. 
Interviews with senior executives and focus groups indicated that four of five organisations showed significant changes in individual cultural dimensions. In comparing the culture attributes including employee participation, goal clarity, organisational identification and focus, management style and locus of authority, considerable variation between firms occurred. In three of the merged entities focus group participants felt that the new entity had a more diffuse and weaker culture and had lost the cultural attributes that had 'glued' the previous firm together. This was especially evident in employees of the acquired firm. Specific changes to cultural dimensions included conflicting managerial styles, with the dominant culture often having a more autocratic style. Organisation restructuring also involved 'hard' HR issues such as rationalising functions and services such as IT, and outsourcing to achieve economies of scale and cut costs. Often this meant formerly decentralised functions being re-centralised, with often traumatic changes in roles and responsibility, job design, authority and accountability. The level of formal/informal relations also changed depending on the culture of the dominant firm. Focus group respondents stated that many employees found these changes particularly difficult to adjust to where a task culture was stronger than a role culture. Therefore the type of organisational culture in each of the firms affects how effectively the new entity deals with 'hard' HR issues. This also affected employee work autonomy, with many feeling marginalised with little support other than from peers.

\section{Human Resource issues and Integration}

With one exception, no formal 'soft' due diligence to determine organisational fit was conducted prior to the transaction. Where due diligence was undertaken, it was financial and strategic. Little evidence exists of prior consideration of organisational fit or human resource issues. A cultural audit or analysis was done in only one of the five companies prior to the M\&A. The use of representative M\&A transition teams and joint steering committees to drive and facilitate the integration, occurred in only two of the companies. The use of integration teams is considered crucial for successful cultural and systemic integration (Tetenbaum, 1999). However, according to employee focus groups, most firms had not implemented a formal merger operations or implementation strategy, nor was the integration actively managed or initiated by a specific person or group. In three out of five firms a clear time perspective was set to achieve M\&A priorities, though most focus group interviewees felt the integration had occurred spontaneously rather than in a planned way and high levels of uncertainty occurred.

There are different perceptions by organisational level of the extent to which a coherent strategy for cultural and HR integration occurs. Employee groups tend to be more critical, while senior executives interviewed felt strategies, either formal or less so, were in place. This suggests that whilst in most cases some action was taken to facilitate change, there was insufficient communication of performance expectations, how changes would affect people or what vision and goals the new organisation sought. Differing perceptions are important, as they may affect morale, motivation and level of trust - factors crucial for effective cultural integration and alignment of HR and other practices. Table 1 provides a summary of key findings focusing on perceived priority differences of senior executives and employees interviewed in focus groups.

Table 1: Human resource and cultural factors in mergers and acquisitions: some key findings

\begin{tabular}{l|c|c}
\hline & $\begin{array}{c}\text { Senior } \\
\text { executives }\end{array}$ & Employees \\
\hline Widely known integration plan & HP & LP \\
\hline Post merger cultural integration plan & LP & LP \\
\hline Integrated HR systems and plan & LP & LP \\
\hline Visible leadership & HP & LP \\
\hline Clearly articulated future goals & HP & LP \\
\hline Functioning integration teams & LP & LP \\
\hline Effective two-way communication & HP & LP \\
\hline Role clarity and performance expectations & HP & LP \\
\hline Making new company an integrated entity & HP & LP \\
\hline Building trust and motivation & HP & HP \\
\hline Managing voluntary staff turnover & LP & LP \\
\hline Sense of urgency and speed & HP & LP \\
\hline
\end{tabular}

Key: Perceived as given high priority (HP)

Perceived as given low priority (LP)

Only one of the respondent firms divided their integration processes into jointly set discernible phases identified by Horwitz (2000), Price (1997) and Ashkenas et al., (1998). In three firms, in the third phase of integration, customer service quality and reliability were negatively affected during this period. This was a view held more strongly by focus group employees than by senior executives interviewed. The focus of the new organisation shifted (temporarily) from its core business to more peripheral activities. A further difference was evident in perceptions and attitudes of employees regarding the culture of the merged company. Although most senior executives of acquired firms felt the merged company operated as an integrated entity, managers and employees of the acquiring organisation held this point to a lesser degree. Lower level employees interviewed in focus groups were more open in voicing criticism and mistrust. They stated that less conscious effort appeared to have been made to foster a cohesive organisational culture, this particularly so in acquired firms.

Two merged firms had a definite sense of urgency during the merger process according to focus group respondents, though senior executives believed there was a greater sense of urgency. Most employees in all focus groups experienced uncertainty regarding their positions in the new organisation following the merger, with one exception where the process was seen as completely transparent. Here a merger map outlining the minutes of the steering committee's meetings, was distributed to all employees. In two firms, focus group data indicated that employees were given an ultimatum to either accept the positions they were offered in the new company or face retrenchment. In addition, finalisation of job roles and positions were communicated verbally to employees at different times, over a period of one week to three months, which further compounded people's anxieties. 


\section{Dealing with employee turnover during a merger or acquisition}

Only one of the companies actively managed employee turnover following the merger according to all groups interviewed. The loss of top management in several cases, through voluntary retrenchment packages, left many feeling insecure and isolated. Staff turnover was not proactively managed and insufficient effort made to retain valuable core competencies. All but one focus group said that not enough attention was given to the acculturation process, actively managing turnover and preventing loss of talented people and core competencies. Communication in four of the five cases was not managed as effectively as possible according to most focus group interviewees. In one firm however, use was made of merger maps with information cascaded through workgroups to the rest of the organisation. The most problematic issue in this regard was undue delays in discussing future roles, career and employment prospects and the goals and vision of the new entity. If the M\&A was a hostile one these problems were more severe and less likely to be addressed in the early transition stage. Focus group interviewees highlighted the need for frequent and honest communication between top management and lower level staff, and improved interpersonal interaction and communication (consistent with Tetenbaum's (1999) HR criteria).

Are organisational structure and managerial styles important in cultural and HR integration?

Most respondents from all groups in acquired firms with a more hierarchical organisation structure initially believed a new flatter structure would limit promotion prospects. But in two of the five firms the latter structure opened up a direct reporting channel to the owners and directors of the organisation. This enabled an increased sense of responsibility, ownership and accountability, and new business units improving systems within the organisation. Management style also changed from being individualistic to more participative. The above confirms that positives change in locus of authority, management style and organisational integration are necessary. In three firms both focus groups and to a lesser extent senior executives felt that their organisations were not operating as fully integrated units, and that this was because of a lack of consultative and communicative managerial styles. There was a significant difference between organisational cultures in most of the cases, and a need to create a unified culture. In firms achieving more effective cultural integration, systems were implemented to share information, employees were more open with each other, and when decisions or changes were made, the effect on the organisation as a whole was considered. These were seen by focus groups as a function of having an appropriate leadership style for M\&A transitions.

\section{Discussion}

\section{Mergers and organisational culture type}

The findings lend support to Cartwright and Cooper's (1996) conclusion that a M\&A will result in a merged entity with cultures dissimilar from their previous ones (Cartwright \& Cooper, 1996). This is less so where the acquired company is smaller, weaker and an inferior performer, with the acquiring firm more likely to impose a dominant culture (Price, 1999). Four of the five M\&A's were combinations of 'role' and 'task' culture types. Where a pre-merger culture is used as a defence mechanism, employees of the acquired firm tended to feel the transaction was a take-over and not a merger. In two firm cases there was evidence of a modern or collaborative marriage with recognition that integration of operations or expertise would be of mutual benefit in integrating the organisations' cultures. Cultural dynamics play a sometimes complex part in the propensity to integrate. Van der Post, De Coning and Smit (1998) and Cartwright and Cooper (1996) note the probability of most cultural dimensions being similar in both organis ations prior to a merger is small. In four of the five M\&A's, characteristics of the dominant culture were prominent in the merged entity. Pritchett and Pound (1997) warn that a 'best of both worlds' strategy can result in instability. Some consider it more difficult and time consuming to blend two cultures than to manage one.

\section{'Soft due diligence', HR and integration strategy}

In most cases the lack of formal 'soft' due diligence had adverse effects. These included a lack of understanding of the differences between organisational cultures and those relating to strategic fit. A culture audit may identify potential problem areas and enable a plan to manage differences. 'Soft' due diligence is essential to assess strengths and weaknesses of respective management teams, to determine an appropriate organisational structure and need for systemic and structural redesign, whether salient differences in corporate culture can be reconciled, and to identify issues which could place the M\&A at risk (Harris, 2000; Pritchett \& Pound, 1997). Three of the case firms did not have a coherent merger integration strategy to identify key managerial roles and processes, and address uncertainty and poor morale. Had management played a more proactive role, feelings of dissonance might have been more effectively eased (Pritchett \& Pound, 1997; Tetenbaum, 1999). Fostering an appropriate culture to support business goals at an early stage affects a meaningful value system and renewed sense of purpose. As managing differences in organis ational culture is complex, adequate resources should be allocated to a senior level integration manager. Momentum Life's merger steering committee and working groups performed a central role in alleviating some of the uncertainty concerning employees' future roles. As in Cisco Systems, those who were directly affected were spoken with face-to-face and informed of what was planned and why. The closure phase or genesis of each merger does not appear to have been achieved, especially in dealing with certain 'hard' HR issues. However, it cannot be assumed that change will occur through the efflux of time. Additional time does not automatically predispose an organisation to change. Rather, cultural integration should be actively managed and the new culture inspired. The fourth stage should be reached to attain closure (Price, 1999). Closure occurs when a unitary or integrated culture has developed and employees internalise the organisation's values and goals. 
Human resource practice support: managing uncertainty and employee turnover

\begin{abstract}
"Having the company you work for acquired is probably the worst thing that can happen to somebody, other than the loss of a family member... All the things you have learnt, all the truths you have known - your boss, where you get your paycheck from, your security - change in one day."
\end{abstract}

Jack Welch, CEO, General Electric, 1995

The management of uncertainty around employment was severely lacking in two of the case studies. After an M\&A announcement employees expect change, but also want clarity of direction and early closure (Tetenbaum, 1999). Prolonged delays erode morale and prolong uncertainty. Although all five cases studied involve recent transitional processes, three firms showed clear evidence of wanting to tighten the transition period. At three firms strategic issues were given a definite time perspective by the new owners. The integration period is likely to depend on organisational size, complexity, and the nature of required changes.

New management may see an M\&A as an ideal opportunity to 'spring clean' and get rid of 'dead wood'. Voluntary retrenchment packages offered to senior employees may not necessarily reflect a well-planned strategy. The potential loss of key players, talent and core competencies is often ignored. Several senior executives in our case firms left voluntarily, finding it difficult to work with new colleagues and accept revised role and status changes. There is often a discernible decrease in managerial posts held after the merger as rationalisation and restructuring occur. Senior employees may leave because of loss of managerial authority, the psychological contract between the individual and the organisation having been broken.

\section{Building organisational and human resource capability}

Effective communication is vital in every phase of the M\&A process (Cartwright \& Cooper, 1996; Price, 1999; Tetenbaum, 1999). While in place, the merger steering committee and working groups at Futuregrowth and Momentum Life were instrumental in this regard. To facilitate communication, they made use of merger maps and cascaded information through workgroups to the rest of the organisation. This allowed a wide range of individuals to contribute information from which decisions regarding the merger process were made. Merger maps were also effective in communicating decisions of the merger steering committee meetings. All findings were transparent and available to anyone who wished to see them. A common problem of lack of adequate communication, is polarisation of attitudes. This was particularly severe in one case. Employees need to be able to voice their fears and criticisms.

As management style and organisational integration are critical aspects in managing M\&A's, special attention should be given to changes in thes e areas (Van der Post et $a l, 1997)$. In three of these M\&A's there were differences in perceptions regarding vision, locus of authority and management style. Unresolved uncertainty regarding roles, authority and responsibility levels and future status, often results in turnover of people the firm may not want to lose. A M\&A may be considered to have stabilised, when a coherent and integrated culture has been institutionalised, with goal clarity, shared values, and defined performance expectations (Cartwright \& Cooper, 1996; Martin, 1985). A shared sense of purpose is vital for rebuilding organisational capabilities and creating sustainable organisational performance. In three case studies with a combination of cultures, there was no absolute change from one culture to another but quite strong traces of each culture remained with employees from both having different perceptions of the new culture. Many felt a sense of loss and powerlessness.

\section{Conclusion and propositions}

Pre-merger planning has a direct impact on post-merger cultural integration. The latter comprises task, role and social integration processes which affect M\&A success. The M\&A processes within four of the five firms did not reflect this 'soft' due diligence prior to the transactions. Only one had a defined integration strategy or a full- time integration team in place. Findings reflect common mistakes which result in unsuccessful cultural transitions. Lessons can be drawn from this investigation to assist organisations in successful mergers, is confirmed. The need for a proactive M\&A approach is a key finding from this investigation and confirms previous research. An independent professional appraisal of the organisations' propensity for a cultural fit is essential. Failures in consolidation are attributed primarily to a lack of an integration plan that focuses on peoplerelated issues (Walker \& Price, 2000). It is important to develop a transition and post merger strategy pre-emptively as opposed to after the roll out. Following our findings and building on the work of Birkinshaw et al (2000), we propose the model in Figure 1 below, for integrating culture and HRM practices.

Employee participation and integration teams may allocate resources, co-ordinate, give focus and guidance, improve morale and enhance implementation effectiveness. Critical HR success factors involve addressing HR issues during strategy development, including HR factors in pre-deal contracts, early induction, training need identification, avoiding hasty decisions on downsizing, productivity improvement, selecting the best people for leadership posts in the merged entity and not awarding all top jobs to the acquirer (Clemente \& Greenspan, 1999). Merger problems often set their own tempo and result in failure because problems spiral out of control. Communicating the rationale behind the decisions, future goals and objectives, new roles and responsibilities, and managerial expectations through constructive dialogue and feedback, are vital to build trust and ensure credible leadership. Preventing the loss of intellectual capital, 'corporate memory' and required core competencies, is critical in building an integrated culture. Employees tend to be distracted during a merger or acquisition, and productivity suffers. This may be interpreted as evidence of a 'bad merger'. 'Morale 
management' and getting employees' support are key to building a successful new organisation. Many 'survivors' suffer from guilt, uncertainty, and further job insecurity.
Strategies are essential to manage the 'survivor syndrome' and focus on the compelling work of integrating two organisations.

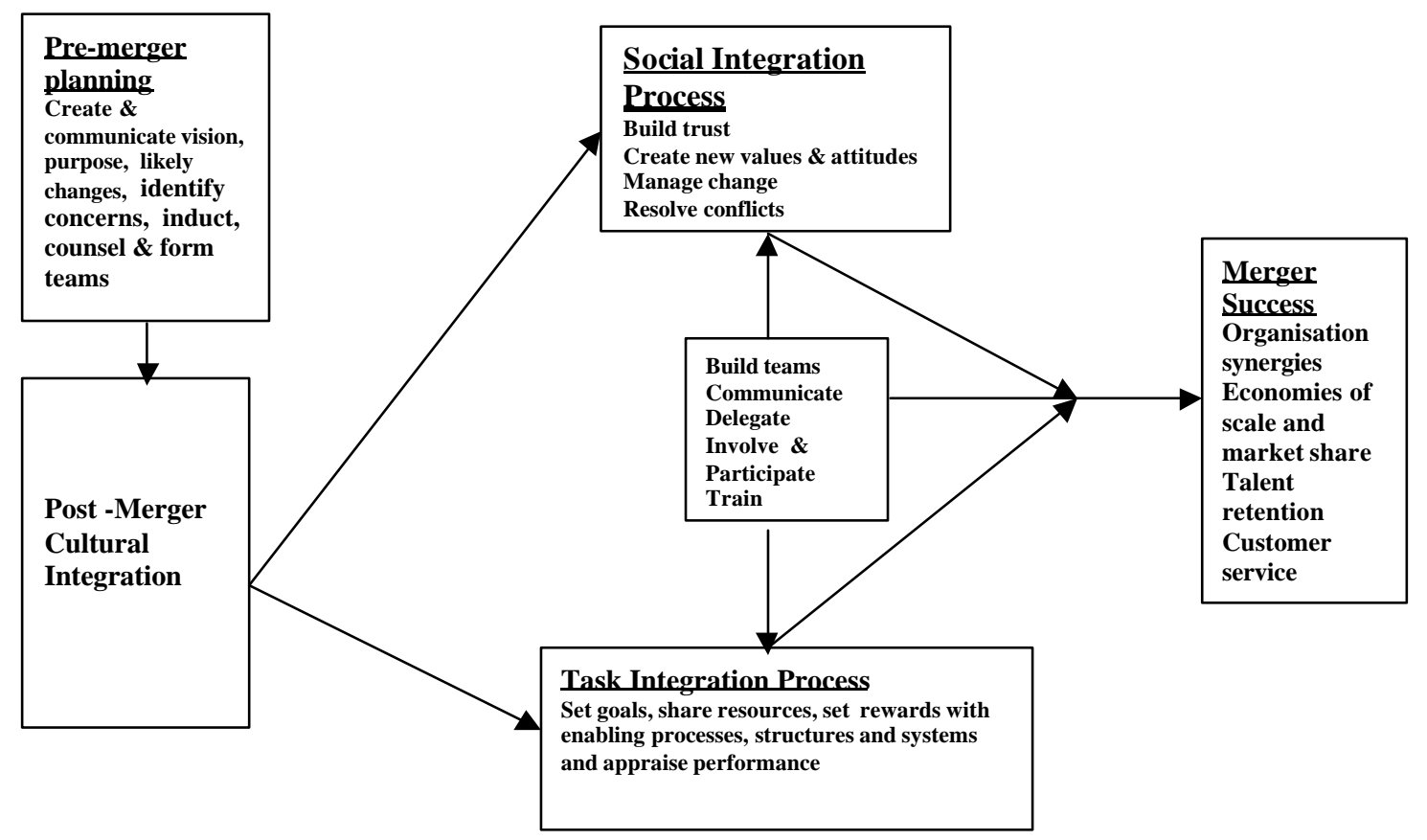

Figure 1: A framework for managing HR and cultural integration before and after a merger

An aim of this study was to determine common themes in M\&A's and the literature. Insights and lessons gleaned are presented to assist managers in future endeavours in this area. Mergers and acquisitions are increasing globally. With the changing diversity of labour markets, diversity within organisational cultures, is increasing. Managing critical success factors identified in this investigation may have direct and indirect impact on productivity, profitability and the success of the merged organisation. Further research into M\&A's in a comparative context is needed. From this investigation it is postulated that national culture context may be less important in within-country M\&A transitions, than organisational culture and generic principles of good practice. National culture will be more important in M\&A's occurring in a cross-cultural context (Perkins, 1999). Future research should focus on a larger sample of cases, considering the relationship of cultural factors with productivity and profitability over a long-term period. Longitudinal ethnographic research would add deeper insight and give a more complete picture of integration and management of organisational culture and their impact on performance and financial success.

\section{References}

Ashkenas, R.N., DeMonaco, L.J. \& Francis, S.C. 1998. 'Making the deal real: How GE Capital integrates acquisitions', Harvard Business Review, January-February: $1-7$.

Bate, P. 1990. Strategies for cultural change. Oxford: Butterworth Heinemann.

Beard, M.J. 1999. 'Developing an effective strategy for international mergers and Acquisitions'. [Online at] www.hr-resource.com/hresources/samp bsamplechapter_01.html.

Bezuidenhout, A. 1999. 'Momentum Southern Life: Examining the effects of organisational culture and profitability during a merger'. Unpublished MBA Research Report, University of Cape Town.

Birkinshaw, J., Bresman, H. \& Hakanson, L. 2000. 'Managing the post-acquisition integration process,' Journal of Management Studies, 37(3):395-425.

Bruckman,J.C. \& Peters, S.C. 1999. 'Mergers and acquisitions: The human equation'. [Online at] http://www.changemanagementgroup.com/mergers.phtml

Cartwright, S. \& Cooper, C.L. 1996. Managing mergers, acquisitions and strategic_alliances: Integrating people and culture. London: Butterworth-Heinemann Ltd. 
Clemente, M. \& Greenspan, D. 1999. Empowering human resources in the merger and acquisition Process. Glen Rock, NJ: Clemente, Greenspan \& Co.

Cohen, S.R. 1999. 'The identification of the corporate cultures in Macsteel (Pty) Ltd and Iscor Steel Ltd Prior to and post merger'. Unpublished MBA Research Report, University of Cape Town.

Dennison, D.R. 1990. Corporate culture and organisational effectiveness. New York: John Wiley \& Son.

Easterby-Smith, M., Thorpe, R. \& Lowe, A. 1991. Management research: An introduction. London: Sage Publication.

Ernst and Young Consultants. 1999. A review of merger and acquisition activity. Johannesburg: Ernst and Young Report.

Fisher, L.M. 1998. Post-merger integration: How Novartis became No. 1. Strategy Business, 11:1-4.

Ghobodian, A., James, P., Liu, J. \& Viney, H. 1999. 'The US takeover of the UK electricity supply industry', Journal of General Management, 24 (3): 3-7.

Harris, S. 2000. 'Mergers: Why they work ... and why they don't' Finance Week, Vol. 12, May: p.3.

Haspeslagh, P. \& Jemison, D. 1991. Managing acquisition: Creating value through corporate renewal. New York: Free Press.

Heller, R. 2000. 'A horizontal future for mergers', Management Today, February: 5-8.

Horwitz, F. 2000. 'Can a hostile takeover succeed?' Breakwater Business, 1(1):20-21. Graduate School of Business University of Cape Town..

Hussey, J. \& Hussey R. 1997. Business research. London: Macmillan Press.

Kellogg, C. \& Silva, W. 1998. 'Does corporate culture really affect mergers and acquisitions?' [Online at] www.wallingfordcapital.com/corpculture htm

Kirsten, F. 1999. 'The effects of mergers and acquisitions on organisational culture, climate and financial performance'. Unpublished MBA Research Report, University of Cape Town.

Kotter, J.P. \& Heskett, J.L. 1992. Corporate culture and performance. New York: The Free Press.

Krugman, P. 2001. 'The price of good mergers is eternal vigilance', The Straits Times, January 16: 25.

Marks, M. \& Mirvis, P.H. 1996. 'The merger syndrome: When corporate cultures clash', Psychology Today, October: 3-6.
Martin, J.1985. Culture, collisions and mergers and acquisitions. In Frost, P.J., Moore, L. Louis, M. Lundberg, C. \& Martin, J. (Eds.). Organisational culture. Beverly Hills, California: Sage Publications.

McDonald, M. 1999. The people side of mergers explore. New York: Free Press.

Mirvis, P.H. 1985. 'Negotiation after the sale', Journal of Occupational Behaviour, 2(2):65-84.

Mosoeunyane, M. \& Thole, K. 2000. 'The effects of culture on a merger: The Futuregrowth case'. Unpublished MBA Dissertation, Graduate School of Business, University of Cape Town.

O'Reilly, C. 1998. 'Cisco Systems: The acquisition of technology is the acquisition of people'. Case HR10, Graduate School of Business, Stanford University.

Perkins, S.J. 1999. Globalization: The people dimension. London: Kogan Page Ltd.

Price, L. 199. 'Helping people stay on their feet during mergers and acquisitions', People Dynamics, 17(10): 36-42.

Pritchett, P. 1985. Managing the shock waves. Dallas, Texas: Pritchett \& Associates, Inc.

Pritchett, P. \& Pound, R. 1997. Smart moves: A crash course on merger integration management. Dallas, Texas: Pritchett \& Associates, Inc.

Rao, B.P. \& Swaminathan,V. 1995. Uneasy alliances: Cultural compatibility or culture shock. New York: Free Press.

Risberg, A. 1997. Communicating for meaning in organisational change. New York: Free Press.

Stopper, W.G. 1998. 'Current practices mergers and acquisitions: Fulfilling the promise,' Human Resource Planning, 22(3):3-6.

Tetenbaum, T.J. 1999. 'Beating the odds of merger and acquisition failure: Seven key practices that improve the chance for expected integration and synergies,' Organisational Dynamics, Autumn: 22-36.

Van der Post, W.Z., De Coning, T.J. \& Smit, E.M. 1998. 'The relationship between organisational culture and financial performance: Some South African evidence,' South African Journal of Business Management, 29(1):3-7.

Van Heerden, A. 1999. 'Protea Industrial Chemicals: A division of Protea Industrial Chemicals (Pty) Ltd: Evaluation of organisational culture pre and post a management buy-out'. Unpublished MBA Research Report, University of Cape Town.

Walker, J.W. \& Price, K.F. 2000. 'Why do mergers go right?', Human Resource Planning, 23(2):6-8. 
Weber, R.P. 1990. Basic content analysis. Boston: Harvard University Press. 